\title{
1 Using Wikipedia page views to explore the cultural importance of global
}

\section{reptiles}

3

4 Uri Roll $^{\mathrm{a}, b^{*}}$, John C. Mittermeier $^{b^{*}}$, Gonzalo I. Diaz ${ }^{c^{*}}$, Maria Novosolov $^{\mathrm{d}}$, Anat Feldman ${ }^{\mathrm{d}}$, Yuval Itescu ${ }^{\mathrm{d}}$,

$5 \quad$ Shai Meiri ${ }^{\mathrm{d}}$ and Richard Grenyer ${ }^{\mathrm{b}}$

6

$7 \quad{ }^{a}$ Department of Zoology, Tinbergen Building, University of Oxford, South Parks Road, Oxford, OX1 3PS,

$8 U K$

$9{ }^{\mathrm{b}}$ School of Geography and the Environment, University of Oxford, South Parks Road, Oxford, OX1 3QY,

$10 U K$

$11{ }^{\mathrm{c}}$ Department of Computer Science, University of Oxford, Wolfson Building, Parks Road, Oxford, OX1

$123 Q D, U K$

$13{ }^{\mathrm{d}}$ Department of Zoology, Tel-Aviv University, Tel-Aviv 6997801, Israel

14

$15 *$ Contributed equally to the paper

16 Corresponding author: Uri Roll, tel: +44(0)7964897746 email: uri.roll@,zoo.ox.ac.uk.

17 
Abstract

Modern conservation operates at the nexus of biological and social influences. While the importance of social and cultural factors are often mentioned, defining, measuring and comparing them remains a significant challenge. Here, we explore a novel method to quantify cultural interest in all extant

22 reptile species using Wikipedia- a large, open-access online encyclopaedia. We analysed all page views of

23 reptile species viewed during 2014 in all of Wikipedia's language editions. We compared species' page

24 view numbers across languages and in relationship to their spatial distribution, phylogeny, threat status

25 and various other biological attributes. We found that while the top three species with respect to page

26 views are shared across major language editions, beyond these, page view ranks of species tend to be

27 specific to particular language editions. Interest within a language is mostly focused on reptiles found in

28 the regions where the language is spoken. Overall, interest is greater for reptiles that are venomous,

29 endangered, widely distributed, larger sized and that have been described earlier. However, within

30 individual families not all the above factors predict page views. Most families contain at least one species

31 in the top 5\% of page views, but 29 families (with 1450 species) have no 'high interest species' in them.

32 Overall, our analyses elucidate novel patterns of human interests in nature over large geographical,

33 cultural and taxonomic spectra using big-data techniques. Such approaches hold much promise for

34 incorporating social perceptions in future conservation practices.

35

36 Keywords ( $\max 6$ ): big data, conservation, culture, endangered, language, flagship species. 


\section{Introduction}

Various cultural elements exert a powerful influence on how conservation attention and resources are allocated. Challenges facing species conservation projects may even be primarily social rather than biological (Kellert 1985; Tisdell 2014). Thus, in order to secure better outcomes for conservation management schemes - in addition to biological attributes - social and cultural variables should also be incorporated in decision making (Ladle and Jepson 2008). Nevertheless, these attributes are often neglected in the conservation decision-making process (Gunnthorsdottir 2001; Kellert 1985; Stokes 2007).

Most global and regional conservation prioritization schemes rely on quantifiable differences in the geographic distribution, population size, ecological role, and evolutionary distinctness of species (Faith 1992; IUCN 2014; Mills et al. 1993; Vane-Wright et al. 1991). However, species are also unequal in their contributions to human culture - in how they are perceived by and attract attention from humans. While a few authors have addressed this point (Cristancho and Vining 2004; Garibaldi and Turner 2004), the extent to which species vary in their cultural importance or impact remains very poorly studied and how this potentially affects conservation practices is mostly unknown. Nevertheless, in order for conservation actions to be fruitful they need to incorporate both traditional conservation parameters and cultural values in local to global scales of the different actors and interventions attempted.

As with other human practices, conservation may suffer from biases due to the non-randomness in human interests and affections. For example we are more interested in the well-being and prolonged persistence of big, 'fluffy', attractive animals (Gunnthorsdottir 2001; Johnson et al. 2010; Ward et al. 1998), those with large, forward facing eyes (Macdonald et al. 2015), those who are more brightly coloured (Prokop and Fančovičová 2013; Stokes 2007) and preferably more phylogenetically (and thus morphologically) close to us (Gunnthorsdottir 2001), etc.

Reptiles as a group are usually less in the public eye when it comes to conservation when compared to the other groups of tetrapods, due to several potential biases and knowledge deficiencies. 
Reptiles comprise about 30\% of all extant land vertebrate species (Meiri and Chapple 2016, this issue),

65

66

67

68 and are likely to have an even greater representation amongst threatened species (IUCN 2014).

Nevertheless, their representation in targeted species conservation schemes is usually much lower (Clucas et al. 2008). Here we list reptiles' representation in targeted species programs of a few global conservation NGOs, acknowledging that local conservation schemes may have different representations of reptiles. Of the World Wildlife Fund's 36 priority species or species groups, only sea turtle and 'Asian tortoises and freshwater turtles' are reptilian (wwf.panda.org). Of the 1031 projects supported by the Mohamed bin Zayed Species Conservation Fund which incorporate tetrapods, only 17\% include reptiles (http://www.speciesconservation.org). None of the African Wildlife Foundation's projects target reptiles (http://www.awf.org). Reptiles comprise 16\% of the specific species of interest listed by the Defenders of Wildlife organization, but only $6.5 \%$ of their animals up for adoption (http://www.defenders.org). While 13 of the 36 species (36\%) under management by the Durrell Wildlife Conservation Trust are reptiles, only one of the 14 species (7\%) up for adoption on their website is a reptile (www.durrell.org).

Furthermore, as compared with mammals and birds, the scientific knowledge of basic biological attributes of reptiles is much lower, and thus so is our ability to develop sound conservation practices addressing their prolonged survival (Böhm et al. 2013; Meiri and Chapple 2016, this issue). For example, while the distributions of all other groups of tetrapods has been known for a decade now (Grenyer et al. 2006; Orme et al. 2005), only recently has a parallel effort been completed for reptiles (www.gardinitiative.org).

Within the $\sim 10300$ recognized species of reptiles (Uetz and Hošek 2015) there are great differences between species in the cultural representations (i.e. appearance at all in the public sphere) and importance in various cultural roles they play. Some reptile species (e.g., venomous snakes, geckos, tortoises) have potent roles across an array of cultural mediums - in the pet trade, as food objects, as fictional characters, as objects of fear or aspiration, etc. (Alves et al. 2009; Alves et al. 2008; Campbell 2009; Klemens and Thorbjarnarson 1995). Nevertheless very many species remain unknown beyond a few herpetology specialists. As such, there are potentially great differences in the contributions of individual reptile species to the various domains of human culture. If conservation hopes to preserve 
features such as the 'aesthetic, historical, and recreational values' of species (Millennium Ecosystems

91 Assessment 2005), then identifying which species contribute to those values is of fundamental

92 importance. Previous studies have examined cultural attitudes towards particular reptile species within

93 local contexts (Ceríaco 2012; Ceríaco et al. 2011; Deb and Malhotra 2001; Jones et al. 2008; Ramstad et

94 al. 2007), yet there have been no global efforts to compare the cultural significance of reptiles. Since

95 many conservation policies and frameworks operate globally, considering cultural value at a global scale

96 is potentially very useful.

97 'Culture' is one of the most widely used terms in the English language (Taras et al. 2009). In the

98 context of conservation, 'cultural value' is frequently applied to defining ways in which humans assign

99 value to different species. Though useful in the abstract, it creates challenges in measuring exactly what it

100 means and creates confusion through the various meanings of value. Here we explore page view statistics

101 (elaborated below) extracted from the Wikipedia online digital text archive for all extant reptiles in all

102 language editions as a measure of the prominence of an entity or idea within a given cultural context ( $\mathrm{Yu}$

103 et al. 2015).

Digital text archives are an increasingly significant resource for the study of human culture and enable questions and scales of investigation that were unfeasible until recently (Aiden and Michel 2013;

106 Lazer et al. 2009; Schich et al. 2014). The use of these resources for studying cultural patterns relevant to 107 conservation is beginning to be recognized but remains low (Arts et al. 2015; Correia et al. 2016). The 108 cultural salience of reptile species could theoretically be studied in a variety of digital archives. Within 109 this context Wikipedia is particularly appealing for several reasons: 1) it is huge (>35 million articles in 110 English to date); 2) it is multilingual (287 languages including 12 with $>1$ million articles); 3 ) it is open 111 access and free to download; 4) it follows a standardized structure that groups information on a species 112 together and thus avoids many of the challenges of unstructured text databases; and 5) a growing body of 113 academic literature addresses aspects of Wikipedia's coverage (Giles 2005; Halavais and Lackaff 2008;

114 Messner and DiStaso 2013; Samoilenko and Yasseri 2014), credibility (Brown 2011; Miller and Murray 
2010; Wilson 2014), contributor demographics (Wilson 2014) and user dynamics (Yasseri et al. 2014; Yasseri et al. 2012).

Wikipedia also has important limitations in the results it can produce and biases in whose cultural information it reflects. Unsurprisingly, Wikipedia skews heavily towards the Global North with respect to both content generation and usage, and African languages in particular are poorly represented (Graham et al. 2014). Wikipedia contributors also tend to be a highly skewed demographic from within the Global North: English-language Wikipedia contributors, for example, are primarily male, and mostly under 29 years old (Wilson 2014). As of 2013, 4.3 million registered users made at least one edit to all of Wikipedia, but only about 130000 registered users made more than 100 edits (Wilson 2014). Another significant challenge in analysing Wikipedia from a cultural standpoint is that some of its contributors are not human. A proportion of Wikipedia articles are created or edited by specialized programs called 'bots'. As an example, one of the most active bots, called 'Lsjbot', has contributed various types of information to over 2.7 million articles. Results obtained from Wikipedia therefore need to be considered within this context. We therefore want to emphasize that Wikipedia should not be seen as reflecting universal values nor representing the voices of groups such as indigenous people or individuals with limited internet access.

Wikipedia provides several potential referential metrics of cultural interest or saliency of different objects, each with potential benefits and flaws. Each Wikipedia page has been created at a particular date, been edited several times by a different number of editors, has a particular length, is linked to and from other pages (within and outside Wikipedia), appears in a set of different language editions, has been viewed a particular number of times, etc. Some of these metrics are potentially very information rich. Unfortunately, many of these metrics may suffer from inherent biases due to bot activity. Therefore - for our initial exploration of this data source for cultural attitudes towards nature - we limited our scope of reference only to the number of page views in different language editions of Wikipedia reptile pages. We suggest that page views within a given language measure the general interest that a page attracts from the public speaking that language (with the above biases in mind). We acknowledge that page views are 
141 recorded in a way that cannot account for page queries made by bots. Nevertheless, as most page views

142 are made by humans (http://stats.wikimedia.org/archive/squid_reports/2014-

143 12/SquidReportCrawlers.htm) we posit that they can provide some insight as to which reptiles attract

144 more interest in the public sphere globally.

145 Here, we provide a novel approach to quantify and compare one aspect of the cultural interest

146 associated with global reptile species - the number of times individual reptile pages are viewed, in a large,

147 user-generated, multi-lingual, online encyclopaedia. We explore patterns at the species level, as many

148 consider species the fundamental unit of biodiversity (Wilson 1992) and many conservation actions are

149 designated towards individual species (Brooks 2010). This enables us to explore i) those species that may

150 have greater conservation value because of their higher cultural interest, and ii) cross-cultural differences

151 in interests towards reptile species, a key attribute in unravelling many conservation challenges. We

152 address three questions relevant to the investigations of culture and conservation: 1) which reptile species

153 are the most culturally salient at the global level, 2) what biological traits characterise those species, and

154 3) how does the relative cultural salience of species vary across languages.

\section{Materials and Methods}

We obtained cultural data on reptile species from two related sources: (i) DBpedia

158 (http://wiki.dbpedia.org, version “Dataset 2014"), a repository of structured data, extracted and curated 159 from Wikipedia, and (ii) Wikidata (http://www.wikidata.org, version 2015-07), a publicly editable 160 repository of structured data, which aims to gather structured data from diverse sources including

161 DBpedia, the Integrated Taxonomic Information System (ITIS - http://www.itis.gov), and many others.

162 For both Wikidata and DBpedia, the full datasets were downloaded. For data processing scripts see the 163 supplementary information.

To extract species-level entities within Wikidata, we utilised the fact that the global taxonomy of

165 life via ITIS is fully integrated into this database. We therefore queried Wikidata for all entities marked as

166 (i) having a 'taxon rank' property (https://www.wikidata.org/wiki/Property:P105) set to the value species 
168 (https://www.wikidata.org/wiki/Property:P225) set to some value (as opposed to no value). Our definition 169 of a species was therefore anything with either a binomial or a 'species' label. Each species in the 170 resulting list - 'Wikidata all species' corresponded to a unique URL within the Wikidata database. We 171 identified reptiles in this list by matching them to Uetz and Hošek (2015) which served as the backbone 172 taxonomy for this work. To obtain information on language editions and page views across languages, we 173 cross-referenced our 'Wikidata reptiles' with DBpedia (data currently not found in Wikidata). DBpedia 174 only includes a language edition for a species if a page for that species exists in a given language. The 175 resulting list 'Wikipedia reptile URLs' contained every page title, in any language, for a species in 176 Wikidata reptiles. We limited our analyses only to those pages that have been viewed at least once: as 177 those that have not been viewed at all are most likely bot-generated pages. Wikipedia page views and article traffic statistics are stored and made publically available at 179 https://wikitech.wikimedia.org/wiki/Analytics/Data/Pagecounts-raw (a third party visualisation tool found 180 at http://stats.grok.se). This dataset consists of files collated on an hourly basis for page views to all 181 Wikipedia articles across all language editions. To extract page views for reptiles we downloaded page 182 view files for the calendar year 2014 (collected per hour), and then matched page titles and their 183 corresponding view counts to Wikipedia reptile URLs. Hourly view counts for each language edition of a 184 species were summed to count total views per species. Altogether we identified 10002 reptile species in 185 Wikidata all species that were viewed in 2014. In order to carry out some first examinations of the patterns of page view activity across reptiles, 187 we assembled various traits per species. Year of description was obtained from Uetz and Hošek (2015).

188 Range sizes of the species as well as global gridded distribution maps on a $1^{0}$ Behrmann equal area 189 projection were obtained from the GARD initiative (www.gardinitiative.org), as was data on the presence 190 of venom. Threat status, for assessed species, were obtained from the IUCN redlist 191 (http://www.iucnredlist.org). Body-size measurements for lepidosaurs were taken from Feldman et al. 192 (2015), and for crocodiles and turtles from Itescu (pers. comm.). Species with unknown or unassessed 
venomous or endangered variables were recorded as 'no'; for IUCN rating any species assessed as VU or

194 above by the IUCN was recorded as 'yes'; any known venomousness of a species was recorded as 'yes'.

195 All the variables were used as a predictor set for a model of page views in total across all language

196 editions, and of the English language edition. Subset models of the total page views for several taxonomic

197 groups were also explored.

We modelled page views using a negative binomial GLM, with the theta parameter estimated from the data by maximum likelihood, as a starting value from a Poisson error model showed problematic over-dispersion. Continuous variables were paired with a quadratic term. We restricted our analyses to 201 those species with complete cases - i.e. without missing values in any of the data columns (for sample 202 sizes see Table 2). Analyses were conducted in R (R-Core-Team 2015) using the glm.nb function in the 203 MASS library (Venables and Ripley 2002). Model averaging was carried out using the MuMIn library 204 (Barton 2015) by all-subsets searches of the complete model (models with only the quadratic term for continuous variables, and not the main term, were excluded). We restricted our analysis to those models within the top 4 AIC units of the best model (Burnham and Anderson 2002). We present coefficients,

207 significance levels, and variable relative importance from the AICc weighted average model assuming a 208 coefficient of zero for variables with no evidence weight in individual models (the "full" coefficient averages in MuMIn). Initially we plotted the median value of the total page views for all the species in each $1^{0}$ grid-

211 cell. We then explored the global distribution patterns of page views in five main Wikipedia language 212 editions, which are not known to have extensive bot edit histories, and are dominant in the countries 213 where they are spoken (Graham et al. 2014) - English, Spanish, Portuguese, German and Japanese. For 214 each language we calculated the total number of page views for each species. We then assigned to each 215 grid cell all the page-views of the species that reside in it and divided this value by the total number of 216 species in that cell with Wikipedia pages in that language. This gave us a measure of the relative visibility 217 in Wikipedia, for each cell, correcting for global trends in species richness. For each reptile family we 218 noted whether it included species found in the top 5 percentile of page views. We then indicated on a tree 
of reptile families based on Reeder et al. (2015) and Pyron and Burbrink (2014) those that do and do not

220 have such 'high interest species'.

222 Results

Extracting page views for the year 2014 resulted in 67062 pages of Wikipedia reptile URLs with

224 at least a single view (138 pages or $0.2 \%$ had only a single view); reptile pages were viewed a total of

22555.5 million times in that year. There were 146 different language editions of Wikipedia with reptile

226 pages in them. Median total views per species is 828.3 , and mean value is 5553.3 giving a very skewed

227 distribution of page views with respect to the species of reptile in question (Figure 1). Eighty two (0.8\%)

228 species received over $50 \%$ of total views, and the top five species received $11.1 \%$ of all the views. The

229 English version has many more page views than the other language editions and comprises $39.4 \%$ of all

230 reptile page views. However, while in English there are about 1850 species with over 1000 page views,

231 there are 3150 species that receive over 1000 page views when all languages editions' page views are

232 combined (Figure 1). Furthermore, $67 \%$ of species with page views in other languages do not even have a

233 Wikipedia page in English. For total page views, and to lesser degree also for English and Spanish, there

234 is a set of several hundreds of species (at the tail end of the distribution) that receive very few views in

235 Wikipedia. Table S1 in the supplement gives the total page view values for all species and for the five

236 main language editions explored.

Table 1 displays the species with the most page views for all of Wikipedia combined and for five chosen Wikipedia language editions. Only three species of reptiles are found in the top 20 page views for

239 all the five languages, Varanus komodoensis - Komodo dragon (top species in overall page views),

240 Crocodylus porosus - salt-water crocodile (third overall) and Dendroaspis polylepis - the black mamba

241 (fourth overall). All three of these species are also the three most visible pages in the English version of

242 Wikipedia. Two more species: Eunectes murinus - the green anaconda ( $7^{\text {th }}$ overall) and Chelonoidis nigra

243 - the Galapagos tortoise $\left(15^{\text {th }}\right.$ overall) are found in the top 20 of four of the five languages. Vipera berus -

244 the common European adder, while being second in total page views is only found in the top 20 of page 
views of the German edition of Wikipedia (out of these five languages). Of the 63 species found in the top 20 of these five language editions only 20 species are shared between more than one language and the rest

247 are unique to a single language.

Our modelling procedure for all reptiles combined, or for reptile groups that have more than 1500 species, highlighted a single model - the full model (with all the parameters included) as having all of the information (over $99 \%$ of the AIC weights). Thus for these groups we report only the results of this model (Table 2). For less speciose groups between 2-14 models contained most of the information (Table 3, for details on the contributing models to each groups' average see Table S2 in the Supplementary Information). Our modelling procedure was able to account for around $60 \%$ of the deviance in page views 254 for all reptile page views in Wikipedia as well as just for the English version of Wikipedia (Table 2).

255 Models for turtles and lizard families had around 10\% less explanatory power (Tables 2, 3). None of the chosen predictors explained important variation in page views of Amphisbaenia. For the analyses of all

257 reptiles, as well as for all lizards, all snakes, and all reptiles in the English version, all the terms we tested in our model proved significant (Table 2). For other subsets, we see that different predictors are highlighted as significant and important (Tables 2,3). The year of the description of the species is an important predictor for all groups, with earlier described species being more visible. Threatened species attract more page views for many groups. Beyond these being venomous is important globally. Body mass is an important positive predictor globally, and for skinks, agamids, chameleons, colubrids and elapids. The size of the distribution range of the species is positively related to page view numbers $\mathrm{s}$ for geckos, agamids, colubrids and vipers. We think it is important to note that the positive relationship between range size and page views is in the opposite direction to the relationship between threat status and page views, suggesting that the threat status relationship is not driven by the small range size of 267 threatened species.

Overall the species of interest to Wikipedia users are found predominantly in North America, Europe and Japan (Figure 2A). However, for individual language editions different patterns arise (Figure 2B-F). English language Wikipedia users predominantly view reptiles living in North America, northern 
271 Europe as well as Indonesia and Eastern Africa (Figure 2B). The Spanish edition's page views highlights

272 species in South America, southern Europe and Southeast Asia (Figure 2C). Portuguese Wikipedia users

273 view species residing in South and Central America, Sub-Saharan Africa and Southeast Asia (Figure 2D).

274 German Wikipedia users mostly view north Palearctic lizards (Figure 2E). Japanese language Wikipedia

275 highlights reptiles from east and Southeast Asia as well as southeast North America, several other regions

276 in eastern South America, the Nile Valley, eastern India and western Southern Africa (Figure 3F).

277 Several patterns arise when looking at the phylogeny highlighting families without

278 representatives in the top five percentile of page views (Figure 3). 29 of the 88 families do not have a

279 single species in the top fifth percentile. Furthermore, several of the unrepresented families - such as

280 Liolaemidae, Gymnophthalmidae and Sphaerodactylidae are speciose (with 286, 243 and 208 species

281 respectively). Altogether about 1450 species are found in sections of the tree without representation. All

282 the families of crocodiles and turtles have at least one highly viewed species in them. However the tuatara

283 (Sphenodon punctatus) is not found in the top five percentile of species' page views. There are three other

284 small clades without any representatives in in the top five percentile. Nevertheless, we note that if we

285 were to choose $5 \%$ of reptile species at random from our sample that would leave on average 33.8

286 families unsampled (standard deviation $=2.9,10000$ randomizations).

287

\section{Discussion}

In recent years there has been a growing interest in people's attitudes towards nature while setting conservation priorities. In most cases, individual surveys were used to gain insight into people's

291 perceptions, preferences and choices about nature (Macdonald et al. 2015; Taras et al. 2009). This

292 approach is labour intensive, and usually limits the scope of the study. Here we utilize, for the first time,

293 an online repository of user-generated content to gain insight into people's interests about an entire class -

294 reptiles - over the entire globe and across many languages. We find interest is greater for reptiles that are

295 venomous, endangered, widely distributed, large and that were described earlier. Furthermore, we show

296 clearly that page views within a language edition increases for species found where that language is 
spoken. This approach holds much promise for the future in elucidating general trends in people's attitudes towards nature and conservation.

The first thing we were able to highlight were those species ranked top overall and top in the different languages (Table 1). It seems that, unsurprisingly, large, poisonous and potentially dangerous 301 animals dominate the top spots: big fierce animals may be rare, but at least in reptiles they also receive 302 disproportionally high internet interest (Figure 1). These are led by the Komodo dragon which alone 303 attracts $3.6 \%$ of total page views, followed by salt-water crocodile and the black mamba. The potential 304 however overstated - for fatal interaction with people, and the associated folklore and cultural salience, is 305 306 clearly a large determinant of page view activity. The same could also be true for the green anaconda (a top 20 species in 4 languages). However, this narrative is clearly not true for the Galapagos giant tortoise which shares prominence with the anaconda. Beyond the shared superstars, language-specific priorities emerge, however they are still driven strongly by venom and the potential for harm. 35 of the 63 top ranked species in the five languages we highlight could potentially be fatal. A large proportion of the top ranked species are also of unusual size. Of the 61 top ranked species in the five languages (with body mass data) $42(68.8 \%)$ are found in the top $5 \%$ of body sizes of all reptiles. Nevertheless, as 82 top ranked

312 species are generating more than half the total page views in our dataset, the vast majority of reptiles 313 which are small, not dangerous and do not have a conservation narrative remain alarmingly invisible. Greater interest or visibility in an online encyclopaedia is nevertheless no guarantee for greater support for targeted conservation of these species - especially for dangerous or venomous animals. However, greater interest could be harnessed to attract support by using both Wikipedia, other online 317 tools and more traditional sources of information and campaigns to acknowledge the ecological roles and 318 importance of these interesting, yet potentially dangerous species. Thus greater cultural interest could turn 319 into greater cultural value. However, this will require a shift in our ideas of what makes a good flagship 320 species - not just large, fluffy, big-eyed animals but potentially also mambas and dragons. The overall 'heat-map' of reptile page views for all Wikipedia language editions combined,

322 resembles that of content generation in Wikipedia in general (Graham et al. 2014). We find that more 
affluent societies with better internet connectivity, which are more represented in Wikipedia activity, are

324 interested predominantly in the species that reside in their surrounding regions (Figure 2A). While the

325 classical latitudinal gradients of species richness highlights tropical richness (Rosenzweig 1995), species

326 of Wikipedia interest mostly inhabit higher latitudes. We present perhaps the first global map of the

327 frequency of interactions with nature of a significant number of people. It is interesting to see its

328 similarity with the general pattern of the Wallacean shortfall in other groups (Whittaker et al. 2005) and

329 perhaps to speculate that they share a mechanism.

Apart from the absolute top 3-5 species, different language editions of Wikipedia highlight

331 different top species of great interest. The local imprint of language becomes very evident when exploring

332 the distributions of the species that receive most page views in the different language editions of

333 Wikipedia (Figure 2B-F). By combining the knowledge of where a language is spoken with the unique page views of different language editions of Wikipedia, our approach enabled us to show that the reptile species people are most interested in, are those which are found where they live. While this phenomenon has been shown before at local scales, for few species (Campos et al. 2012; Lindemann-Matthies 2005;

337 Shwartz et al. 2013), here we show it for an entire class of organism at a global scale. These findings 338 further support the importance of regional conservation management plans which target the species considered important by those people most affected by and involved in their conservation (Miller 2005). Our models were able to explain much of the variance in the interest people have in different 341 species, using biological and other traits of the species (Table 2). The importance of description year 342 perhaps highlights that similar mechanisms were at play for the selection of species to describe by the 343 early reptile taxonomists as they are today for the general internet-using public. People are also more 344 interested in large and venomous reptiles (Gunnthorsdottir 2001; Johnson et al. 2010; Ward et al. 1998; 345 Woods 2000). Importantly, we find that species listed by the IUCN as threatened with extinction attract 346 more interest (see also Johnson et al. 2010), irrespective of their body size, distribution or venomous 347 status. This finding suggests that the IUCN red-listing process has intrinsic cultural impact, at least for 348 reptiles (Ceballos and Ehrlich 2002). Models for selected reptile families and major groups show group- 
specific differences in the importance and significance of particular variables (but are always congruent in

350 sign with each other and with the overall reptile models). Consequently, interest between particular reptile 351 groups are likely to be influenced by different factors. This finding could be of value when searching for 352 effective flagship species for conservation (Barua et al. 2011; Verissimo et al. 2011).

353 Following the notion of protecting unique evolutionary linages or phylogenetic diversity (PD) we 354 plotted on a family-level tree of reptiles those families that have at least one representative species which 355 is highly visible in Wikipedia (Figure 3). We find species in the top 5\% of page views to be distributed 356 widely across the phylogeny, leaving $33 \%$ of the 88 reptile families but only four distinct clades without a 357 species of high interest. How interest, as measured by page views, relates to protection of phylogenetic 358 diversity of course depends upon how we think interest influences conservation action. One conservative 359 interpretation would simply be that a set of high-interest species exists which as passive recipients of 360 conservation action, might effectively sample the phylogeny. At the other extreme, we could argue for 361 direct use of page views as a measure of conservation importance. Page views in an online encyclopaedia 362 are a quantifiable, omnipresent and easily obtainable metric of cultural interest, and could have obvious 363 pragmatic benefits. Perhaps adopting such a metric together with other common conservation measures 364 (threat, PD, function diversity etc) could bring about a more holistic suite of parameters for designating 365 species for conservation.

366 Using large online repositories and big-data approaches holds much promise for conservation 367 biology (Correia et al. 2016). We present an initial exploration of reptile species viewed in different 368 language editions of Wikipedia. Interpreting these results should be done with caution as there are several 369 known biases inherent to Wikipedia (Brown 2011; Graham et al. 2014; Miller and Murray 2010; Wilson 370 2014). As Arts et al. (2015) state, new technologies in conservation show "a need for rigorous evaluation 371 [and] more comprehensive consideration of social exclusion". Wikipedia page views, if applied 372 uncritically as measures of conservation priority, would directly exclude the cultural values of the 373 majority of humanity. Nevertheless, as an increasing amount of human activity is represented online and 374 more tools for analysing this activity are being developed and tested, such approaches as ours become 
375 more useful and comparable. Exploring patterns of other metrics within Wikipedia, as well as other

376 digital text corpuses with perhaps either more inclusive, or more targeted cultural salience, could be very

377 useful. Trying to match these broad online survey techniques with more traditional surveys could prove

378 useful, as theories and methods for the latter are much more robust. As challenges of protecting

379 biodiversity are increasing, we need to develop new tools, approaches and mind-sets to tackle it (Sharman

380 and Mlambo 2012) here we provide such an example.

381 


\section{$382 \quad$ Acknowledgments}

We would like to thank all the members of the GARD consortium for providing data on reptile

384 distributions. We would also like to thank David Chapple and three anonymous reviewers for insightful

385 comments on earlier versions of this paper.

386

387

388 Conflict of Interest

389

All Authors claim no conflict of interest.

390 


\section{References}

Aiden, E., Michel, J.-B., 2013. Uncharted: Big Data as a Lens on Human Culture. Riverhead Books, New York, New York, USA.

Alves, R.R.N., Léo Neto, N.A., Santana, G.G., Vieira, W.L.S., Almeida, W.O., 2009. Reptiles used for medicinal and magic religious purposes in Brazil. Applied Herpetology 6, 257-274.

Alves, R.R.N., Vieira, W.L.S., Santana, G.G., 2008. Reptiles used in traditional folk medicine: conservation implications. Biodiversity and Conservation 17, 2037-2049.

Arts, K., van der Wal, R., Adams, W.M., 2015. Digital technology and the conservation of nature. Ambio 44, 661-673.

Barton, K., 2015. MuMIn: Multi-Model Inference.

Barua, M., Root-Bernstein, M., Ladle, R., Jepson, P., 2011. Defining Flagship Uses is Critical for Flagship Selection: A Critique of the IUCN Climate Change Flagship Fleet. Ambio 40, 431-435.

Böhm, M., Collen, B., et al. 2013. The conservation status of the world's reptiles. Biological Conservation $157,372-385$.

Brooks, T., 2010. Conservation planning and priorities, In Conservation Biology for All. eds N.S. Sodhi, P.R. Ehrlich, pp. 199-219. Oxford University Press, Oxford, UK.

Brown, A.R., 2011. Wikipedia as a data source for political scientists: Accuracy and completeness of coverage. PS: Political Science \& Politics 44, 339-343.

Burnham, K.P., Anderson, D.R., 2002. Model selection and multimodel inference: a practical information-theoretic approach., 2nd edn. Springer-Verlag, New York.

Campbell, M., 2009. Repositioning zoogeography within the nature-culture borderlands: An animal geography of reptiles in southern Ghana. Applied Geography 29, 260-268.

Campos, C.M., Greco, S., Ciarlante, J.J., Balangione, M., Bender, J.B., Nates, J., Lindemann-Matthies, P., 2012. Students' familiarity and initial contact with species in the Monte desert (Mendoza, Argentina). Journal of Arid Environments 82, 98-105. 
Ceballos, G., Ehrlich, P.R., 2002. Mammal population losses and the extinction crisis. Science 296, 904907.

Ceríaco, L.M.P., 2012. Human attitudes towards herpetofauna: the influence of folklore and negative values on the conservation of amphibians and reptiles in Portugal. Journal of Ethnobiology and Ethnomedicine 8, 8 .

Ceríaco, L.M.P., Marques, M.P., Madeira, N.C., Vila-Viçosa, C.M., Mendes, P., 2011. Folklore and traditional ecological knowledge of geckos in Southern Portugal: implications for conservation and science. Journal of Ethnobiology and Ethnomedicine 7, 1-10.

Clucas, B., McHugh, K., Caro, T., 2008. Flagship species on covers of US conservation and nature magazines. Biodiversity and Conservation 17, 1517-1528.

Correia, R.A., Jepson, P.R., Malhado, A.C.M., Ladle, R.J., 2016. Familiarity breeds content: assessing bird species popularity with culturomics. PeerJ 4, e1728.

Cristancho, S., Vining, J., 2004. Culturally defined keystone species. Human Ecology Review 11, 153 164.

Deb, D., Malhotra, K.C., 2001. Conservation Ethos in Local Traditions: The West Bengal Heritage. Society \& Natural Resources 14, 711-724.

Faith, D.P., 1992. Conservation evaluation and phylogenetic diversity. Biological Conservation 61, 1-10.

Feldman, A., Sabath, N., Pyron, R.A., Mayrose, I., Meiri, S., 2015. Body-sizes and diversification rates of lizards, snakes, amphisbaenians and the tuatara. Global Ecology and Biogeography In Press.

Garibaldi, A., Turner, N., 2004. Cultural keystone species: implications for ecological conservation and restoration. Ecology and Society $9,1$.

Giles, J., 2005. Internet encyclopaedias go head to head. Nature 438, 900-901.

Graham, M., Hogan, B., Straumann, R.K., Medhat, A., 2014. Uneven Geographies of User-Generated Information: Patterns of Increasing Informational Poverty. Annals of the Association of American Geographers 104, 746-764. 
441 Grenyer, R., Orme, C.D.L., Jackson, S.F., Thomas, G.H., Davies, R.G., Davies, T.J., Jones, K.E., Olson, V.A., Ridgely, R.S., Rasmussen, P.C., Ding, T.S., Bennett, P.M., Blackburn, T.M., Gaston, K.J., Gittleman, J.L., Owens, I.P.F., 2006. Global distribution and conservation of rare and threatened vertebrates. Nature 444, 93-96.

Gunnthorsdottir, A., 2001. Physical attractiveness of an animal species as a decision factor for its preservation. Anthrozoos 14, 204-215.

Halavais, A., Lackaff, D., 2008. An analysis of topical coverage of Wikipedia. Journal of ComputerMediated Communication 13, 429-440.

IUCN, 2014. The IUCN Red List of Threatened Species. Version 2014.3.

Johnson, P.J., Kansky, R., Loveridge, A.J., Macdonald, D.W., 2010. Size, Rarity and Charisma: Valuing African Wildlife Trophies. PLoS ONE 5, e12866.

Jones, J.P.G., Andriamarovololona, M.M., Hockley, N., 2008. The Importance of Taboos and Social Norms to Conservation in Madagascar. Conservation Biology 22, 976-986.

Kellert, S.R., 1985. Social and perceptual factors in endangered species management. The Journal of Wildlife Management 49, 528-536.

Klemens, M.W., Thorbjarnarson, J.B., 1995. Reptiles as a food resource. Biodiversity and Conservation 4, 281-298.

Ladle, R.J., Jepson, P., 2008. Toward a biocultural theory of avoided extinction. Conservation Letters 1, $111-118$.

Lazer, D., Pentland, A.S., Adamic, L., Aral, S., Barabasi, A.L., Brewer, D., Christakis, N., Contractor, N., Fowler, J., Gutmann, M., 2009. Life in the network: the coming age of computational social science. Science 323, 721-723.

Lindemann-Matthies, P., 2005. 'Loveable' mammals and 'lifeless' plants: how children's interest in common local organisms can be enhanced through observation of nature. International journal of science education $27,655-677$. 
Macdonald, E.A., Burnham, D., Hinks, A.E., Dickman, A.J., Malhi, Y., Macdonald, D.W., 2015. Conservation inequality and the charismatic cat: Felis felicis. Global Ecology and Conservation 3, $851-866$

Meiri, S., Chapple, D.G., 2016. Biases in the current knowledge of threat status in lizards, and bridging the 'assessment gap'. Biological Conservation, reptile conservation special issue.

Messner, M., DiStaso, M.W., 2013. Wikipedia versus Encyclopedia Britannica: A longitudinal analysis to identify the impact of social media on the standards of knowledge. Mass Communication and Society 16, 465-486.

Millennium Ecosystems Assessment, 2005. Ecosystems and Human Well-Being: Biodiversity Synthesis. World Resources Institute, Washington, D.C.

Miller, J.C., Murray, H.B., 2010. Wikipedia in court: When and how citing Wikipedia and other consensus websites is appropriate. St. John's Law Review 84, 633-656.

Miller, J.R., 2005. Biodiversity conservation and the extinction of experience. Trends in Ecology \& Evolution 20, 430-434.

Mills, L.S., Soulé, M.E., Doak, D.F., 1993. The keystone-species concept in ecology and conservation. Bioscience 43, 219-224.

Orme, C.D.L., Davies, R.G., Burgess, M., Eigenbrod, F., Pickup, N., Olson, V.A., Webster, A.J., Ding, T.S., Rasmussen, P.C., Ridgely, R.S., Stattersfield, A.J., Bennett, P.M., Blackburn, T.M., Gaston, K.J., Owens, I.P.F., 2005. Global hotspots of species richness are not congruent with endemism or threat. Nature 436, 1016-1019.

Prokop, P., Fančovičová, J., 2013. Does colour matter? The influence of animal warning coloration on human emotions and willingness to protect them. Animal Conservation 16, 458-466.

Pyron, R.A., Burbrink, F.T., 2014. Early origin of viviparity and multiple reversions to oviparity in squamate reptiles. Ecology Letters 17, 13-21.

R-Core-Team, 2015. R: A language and environment for statistical computing. R Foundation for Statistical Computing, Vienna, Austria. 
Ramstad, K.M., Nelson, N.J., Paine, G., Beech, D., Paul, A., Paul, P., Allendorf, F.W., Daugherty, C.H., 2007. Species and cultural conservation in New Zealand: maori traditional ecological knowledge of tuatara. Conservation Biology 21, 455-464.

Reeder, T.W., Townsend, T.M., Mulcahy, D.G., Noonan, B.P., Wood, P.L., Jr., Sites, J.W., Jr., Wiens, J.J., 2015. Integrated Analyses Resolve Conflicts over Squamate Reptile Phylogeny and Reveal Unexpected Placements for Fossil Taxa. PLoS ONE 10, e0118199.

Rosenzweig, M.L., 1995. Species diversity in space and time. Cambridge University Press, Cambridge, UK.

Samoilenko, A., Yasseri, T., 2014. The distorted mirror of Wikipedia: a quantitative analysis of Wikipedia coverage of academics. EPJ Data Science 3, 1-11.

Schich, M., Song, C., Ahn, Y.-Y., Mirsky, A., Martino, M., Barabási, A.-L., Helbing, D., 2014. A network framework of cultural history. Science 345, 558-562.

Sharman, M., Mlambo, M.C., 2012. Wicked: The problem of biodiversity loss. GAIA-Ecological Perspectives for Science and Society 21, 274-277.

Shwartz, A., Cheval, H., Simon, L., Julliard, R., 2013. Virtual Garden Computer Program for use in Exploring the Elements of Biodiversity People Want in Cities. Conservation Biology 27, 876-886.

Stokes, D.L., 2007. Things we like: human preferences among similar organisms and implications for conservation. Human Ecology 35, 361-369.

Taras, V., Rowney, J., Steel, P., 2009. Half a century of measuring culture: Review of approaches, challenges, and limitations based on the analysis of 121 instruments for quantifying culture. Journal of International Management 15, 357-373.

Tisdell, C.A., 2014. Human Values and Biodiversity Conservation: The Survival of Wild Species. Edward Elgar Publishing, Cheltenham, UK.

Uetz, P., Hošek, J., 2015. The Reptile Database.

Vane-Wright, R.I., Humphries, C.J., Williams, P.H., 1991. What to protect? - Systematics and the agony of choice. Biological Conservation 55, 235-254. 
Venables, W.N., Ripley, B.D., 2002. Modern Applied Statistics with S., 4th edn. Springer, New York, USA.

Verissimo, D., MacMillan, D.C., Smith, R.J., 2011. Toward a systematic approach for identifying conservation flagships. Conservation Letters 4, 1-8.

Ward, P.I., Mosberger, N., Kistler, C., Fischer, O., 1998. The relationship between popularity and body size in zoo animals. Conservation Biology 12, 1408-1411.

Whittaker, R.J., Araujo, M.B., Jepson, P., Ladle, R.J., Watson, J.E., Willis, K.J., 2005. Conservation biogeography: assessment and prospect. Diversity and Distributions 11, 3-23.

Wilson, E.O., 1992. The Diversity of Life. Belknap, Cambridge, Massachusetts.

Wilson, J.L., 2014. Proceed with Extreme Caution: Citation to Wikipedia in Light of Contributor Demographics and Content Policies. Vanderbilt Journal of Entertainment \& Technology Law 16, $857-908$.

Woods, B., 2000. Beauty and the beast: preferences for animals in Australia. Journal of Tourism Studies 11, 25-35.

Yasseri, T., Spoerri, A., Graham, M., Kertész, J., 2014. The most controversial topics in Wikipedia: A multilingual and geographical analysis, In Global Wikipedia: International and cross-cultural issues in online collaboration eds F. P., H. N. Scarecrow Press

Yasseri, T., Sumi, R., Rung, A., Kornai, A., Kertész, J., 2012. Dynamics of conflicts in Wikipedia. PLoS ONE 7, 1-12.

Yu, A.Z., Ronen, S., Hu, K., Lu, T., Hidalgo, C.A., 2015. Pantheon: A Dataset for the Study of Global Cultural Production. arXiv:1502.07310v1 [physics.soc-ph]. 


\section{Tables}

\begin{tabular}{|c|c|c|c|c|c|c|c|}
\hline Total & English & Spanish & Portuguese & German & Japanese & Binomial & $\begin{array}{l}\# \\
\text { top }\end{array}$ \\
\hline Varanus komodoensis (2014932) & Varanus komodoensis (845265) & Iguana iguana (196312) & $\begin{array}{l}\text { Varanus komodoensis } \\
(110791)\end{array}$ & Natrix natrix (251174) & Gloydius blomhoffii (191748) & Crocodylus porosus & 5 \\
\hline Vipera berus (1059665) & Dendroaspis polylepis (520406) & $\begin{array}{l}\text { Varanus komodoensis } \\
(155033)\end{array}$ & $\begin{array}{l}\text { Chelonoidis carbonaria } \\
(64113)\end{array}$ & Vipera berus (223389) & Protobothrops flavoviridis (160635) & Dendroaspis polylepis & 5 \\
\hline Crocodylus porosus (1055428) & Crocodylus porosus (478207) & Boa constrictor (97573) & Caretta caretta (59071) & Anguis fragilis (181409) & Elaphe climacophora (134282) & Varanus komodoensis & 5 \\
\hline Dendroaspis polylepis (1042072) & Ophiophagus hannah (439853) & Eunectes murinus (86817) & Boa constrictor (45784) & Eunectes murinus (151228) & Gekko japonicus (127422) & Chelonoidis nigra & 4 \\
\hline Ophiophagus hannah (1008676) & Heloderma suspectum (396522) & Crocodylus porosus (60603) & Caiman latirostris (39123) & $\begin{array}{l}\text { Varanus komodoensis } \\
(130003)\end{array}$ & Rhabdophis tigrinus (126388) & Eunectes murinus & 4 \\
\hline Natrix natrix (949592) & Agkistrodon piscivorus (315207) & Dermochelys coriacea (57041) & Dendroaspis polylepis (37993) & Zamenis longissimus (88508) & $\begin{array}{l}\text { Takydromus tachydromoides } \\
\text { (97362) }\end{array}$ & Boa constrictor & 3 \\
\hline Eunectes murinus (929057) & $\begin{array}{l}\text { Alligator mississippiensis } \\
(266741)\end{array}$ & $\begin{array}{l}\text { Eretmochelys imbricata } \\
\text { (52099) }\end{array}$ & Crocodylus porosus (34337) & Lacerta agilis (84408) & Varanus komodoensis (97124) & Crocodylus niloticus & 3 \\
\hline Boa constrictor (629112) & Dermochelys coriacea (254229) & Dendroaspis polylepis (51405) & Bothrops jararaca (28880) & Testudo hermanni (80563) & Pelodiscus sinensis (94847) & Dermochelys coriacea & 3 \\
\hline Anguis fragilis (616326) & Crocodylus niloticus (240528) & Caiman yacare (51215) & Bothrops alternatus (27771) & Dendroaspis polylepis (79740) & Trachemys scripta (72495) & Ophiophagus hannah & 3 \\
\hline Crocodylus niloticus (613623) & Boa constrictor (240469) & Caretta caretta (49466) & Python regius (27680) & Crocodylus porosus (76318) & Elaphe quadrivirgata (63705) & Caiman yacare & 2 \\
\hline Dermochelys coriacea (559746) & Eunectes murinus (233751) & Crocodylus acutus (47570) & Lachesis muta (27530) & Ophiophagus hannah (62606) & Ophiophagus hannah (61424) & Caretta caretta & 2 \\
\hline Heloderma suspectum (521818) & $\begin{array}{l}\text { Agkistrodon contortrix (225881) } \\
\text { Macrochelys temminckii }\end{array}$ & $\begin{array}{l}\text { Chelonia mydas (47417) } \\
\text { Chelonoidis carbonaria }\end{array}$ & Bothrops insularis (25673) & $\begin{array}{l}\text { Oxyuranus microlepidotus } \\
(62434)\end{array}$ & Plestiodon japonicus (57898) & Chelonia mydas & 2 \\
\hline Iguana iguana (498330) & $(204320)$ & $(41247)$ & Caiman yacare (23431) & Vipera aspis (55498) & Chelydra serpentina (55670) & Chelonoidis carbonaria & 2 \\
\hline Caretta caretta (476772) & Crocodylus acutus (201540) & Caiman crocodilus (33843) & Spilotes pullatus (23058) & Chelonoidis nigra (55451) & Crocodylus porosus (55111) & Chelydra serpentina & 2 \\
\hline Chelonoidis nigra (471396) & Chelonoidis nigra (200239) & Bothrops asper (32822) & $\begin{array}{l}\text { Hemidactylus mabouia } \\
\text { (21975) }\end{array}$ & Python molurus (52781) & Mauremys reevesii (47096) & Crocodylus acutus & 2 \\
\hline Chelonia mydas (458579) & Gavialis gangeticus (199622) & Bothrops atrox (32577) & Bothrops jararacussu (20316) & Coronella austriaca (46730) & Dendroaspis polylepis (41840) & Eretmochelys imbricata & 2 \\
\hline Malayopython reticulatus (432497) & Python bivittatus (198632) & Chelonoidis nigra (30041) & Dermochelys coriacea (19032) & Python regius (40647) & Macrochelys temminckii (40402) & Macrochelys temminckii & 2 \\
\hline Alligator mississippiensis (425631) & Chelydra serpentina (190934) & Tarentola mauritanica (28872) & Melanosuchus niger (19027) & Crocodylus niloticus (40644) & Mauremys japonica (37894) & Oxyuranus microlepidotus & 2 \\
\hline Gavialis gangeticus (393183) & Chelonia mydas (182412) & Vipera aspis (27377) & $(18853)$ & Oxyuranus scutellatus (39910) & Eunectes murinus (35703) & Python regius & 2 \\
\hline Agkistrodon piscivorus (391239) & $(173869)$ & Crocodylus niloticus (27351) & Chelonoidis nigra (18212) & Emys orbicularis (37246) & Malayopython reticulatus (34727) & Vipera aspis & 2 \\
\hline
\end{tabular}


543 Table 1: Species rank for total page views across all languages and for five key language editions. The top 20 species for all of Wikipedia and five key

544 language editions are shown and ordered from top to bottom, with page views given in parenthesis. Species appearing in more than one language

545 edition are colour-coded according to the column on the right. 


\begin{tabular}{|c|c|c|c|c|c|c|c|c|c|c|}
\hline & \multicolumn{2}{|c|}{ All reptiles } & \multicolumn{2}{|c|}{$\begin{array}{c}\text { All reptiles } \\
\text { (English) }\end{array}$} & \multicolumn{2}{|c|}{ Snakes } & \multicolumn{2}{|c|}{ Lizards } & \multicolumn{2}{|c|}{ Scincidae } \\
\hline & coeff. & $\mathrm{P}$ & coeff. & $\mathrm{P}$ & coeff. & $\mathrm{P}$ & coeff. & $\mathrm{P}$ & coeff. & $\mathrm{P}$ \\
\hline Venomousness & 0.346 & $* * *$ & 0.397 & $* * *$ & 0.667 & $* * *$ & 1.685 & $* * *$ & $\mathrm{n} / \mathrm{a}$ & \\
\hline Threat & 0.733 & $* * *$ & 0.288 & $* * *$ & 0.643 & $* * *$ & 0.739 & $* * *$ & 0.340 & $* * *$ \\
\hline Body mass & -0.145 & $* * *$ & -0.092 & $* * *$ & -0.501 & $* * *$ & -0.072 & $* * *$ & 0.061 & \\
\hline Body mass ${ }^{2}$ & 0.052 & $* * *$ & 0.036 & $* * *$ & 0.088 & $* * *$ & 0.051 & $* * *$ & 0.021 & $* *$ \\
\hline Description year & -0.214 & $* * *$ & -0.116 & $* * *$ & -0.250 & $* * *$ & -0.205 & $* * *$ & -0.177 & $* * *$ \\
\hline Description year $^{2}$ & $5.3 \mathrm{E}-05$ & $* * *$ & $2.9 \mathrm{E}-05$ & $* * *$ & $6.3 \mathrm{E}-05$ & $* * *$ & $5.1 \mathrm{E}-05$ & $* * *$ & 4.4E-05 & $* * *$ \\
\hline Area & -0.117 & $* * *$ & -0.170 & $* * *$ & -0.111 & $* * *$ & -0.152 & $* * *$ & -0.105 & $* * *$ \\
\hline Area $^{2}$ & 0.009 & $* * *$ & 0.013 & $* * *$ & 0.009 & $* * *$ & 0.012 & $* * *$ & 0.006 & $* * *$ \\
\hline $\mathrm{n}$ & 9701 & & 3115 & & 3353 & & 5932 & & 1557 & \\
\hline Adjusted $D^{2}$ & 0.671 & & 0.579 & & 0.670 & & 0.623 & & 0.470 & \\
\hline
\end{tabular}

547 Table 2: Modelling page views with various traits. The results of modelling page views with negative binomial GLMs and quadratic terms for

548 continuous variables. Models are for all page views for all species and English page view for all species. Models for snakes, lizards (includes

549 Sphenodon) and Scincidae are for total page views. Results are for the global models of these groups which includes all terms (see text). coeff. denotes

550 coefficients. Asterisks denote p values $-* *<0.01, * * *<0.001$. 


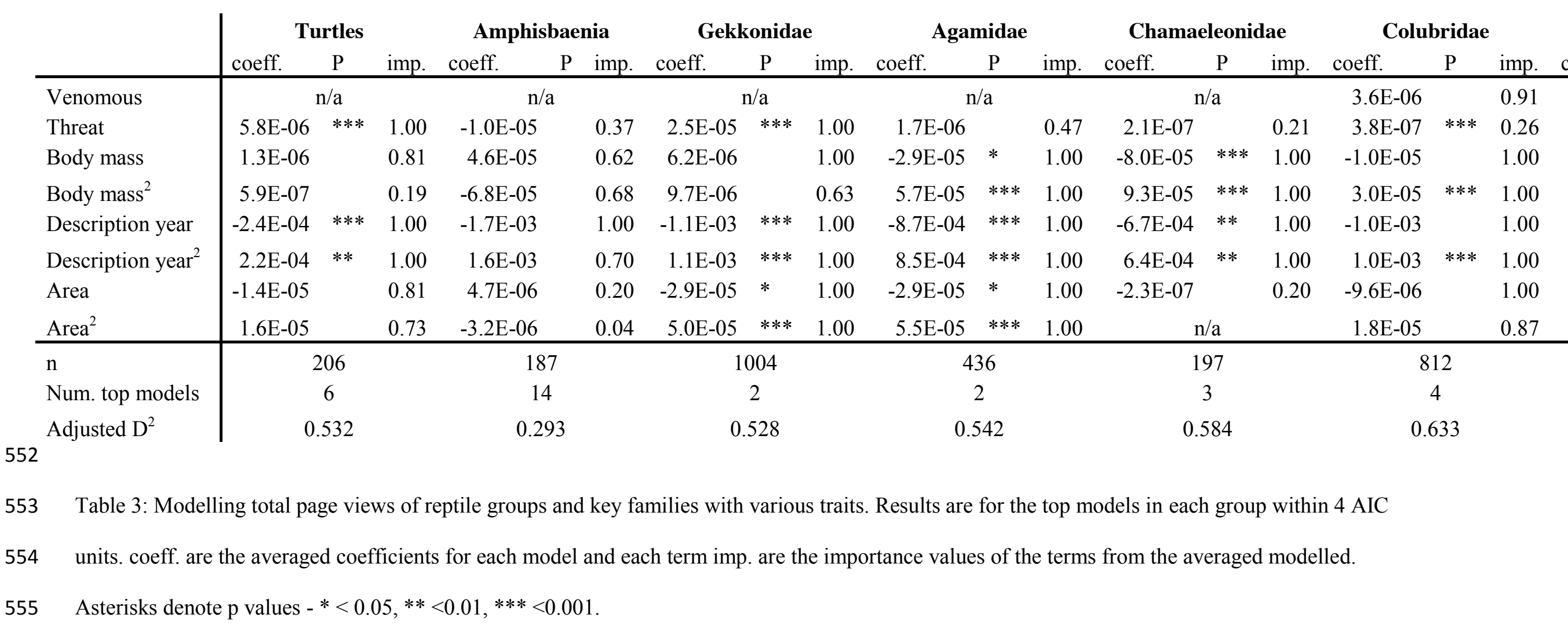




\section{$556 \quad$ Figure Captions}

557 Figure 1: The abundance and frequency distribution of page views. The main pane shows the 558 ranked abundance distribution for $\ln$ transformed total page views and views of five main 559 families. The inset shows the frequency distribution of log transformed total page views.

561 Figure 2: Global distribution maps of page views of reptiles. Pane A displays the median value of 562 the total page views for all the species, calculated per grid cell. Panes B-F show patterns of page 563 views in five main Wikipedia language- English (B), Spanish (C), Portuguese (D), German (E) 564 and Japanese (F). Each of these panes shows total number of page views per gridcell in that 565 language divided by the number of species in that cell with Wikipedia pages in that particular 566 language.

568 Figure 3: Phylogeny of reptile families. Family branches coloured red are those without a single 569 species represented in the top 5 percentile of total page views. 


\section{Supplementary tables:}

572 Table S1: Page views of reptiles pages in Wikipedia in the year 2014. The table displays the total

573 page views from all 146 Wikipedia language editions, as well as, those for five key languages:

574 English, Spanish, Portuguese, German and, Japanese (Portug.). Reptile binomial names follow

575 the August 2015 Uetz and Hošek taxonomy.

576 Table S2: Details on individual model contributing to the model averaging for the different

577 groups.

578 
$580 \quad$ Figure 1

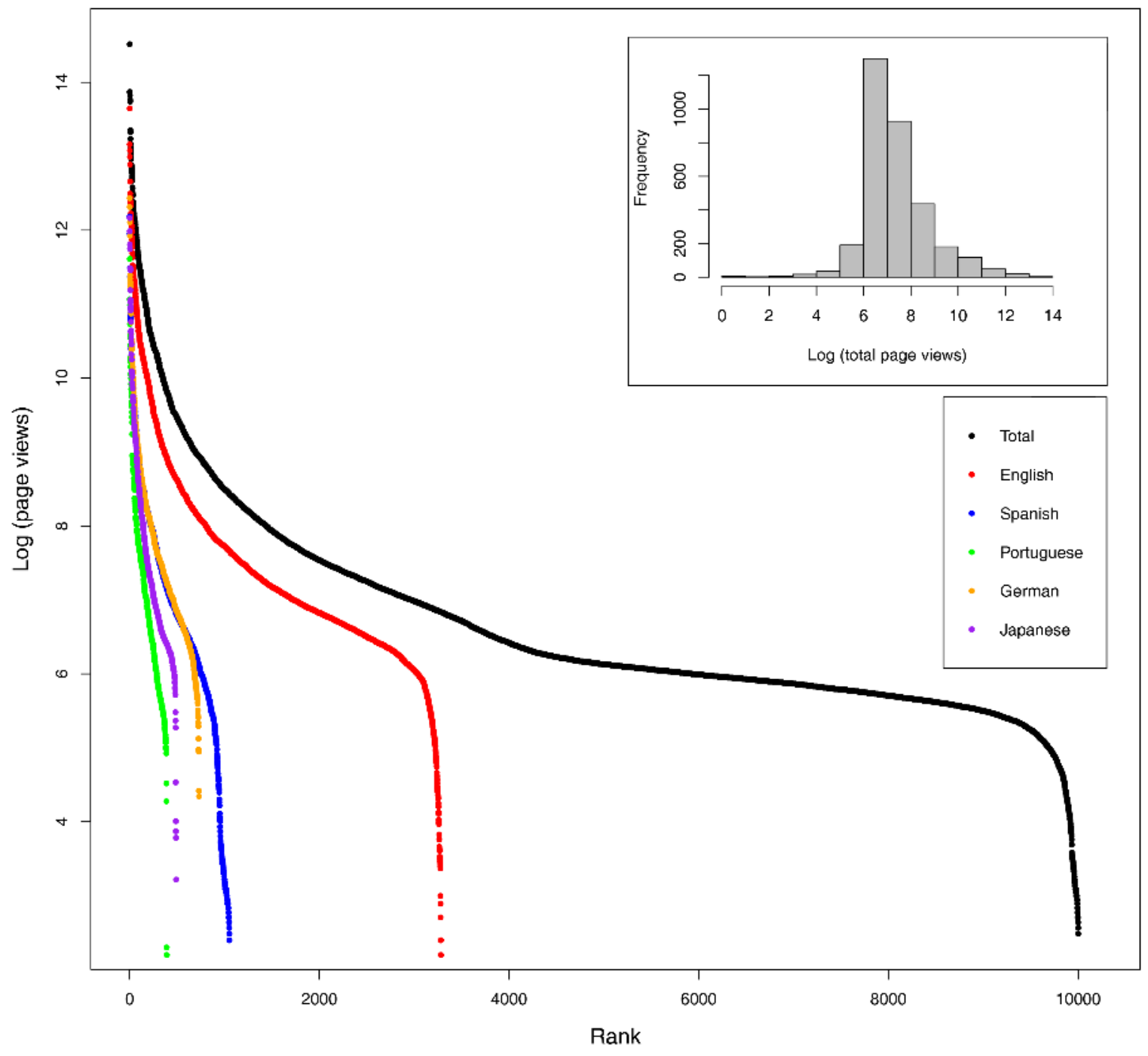

581

582 
Figure 2

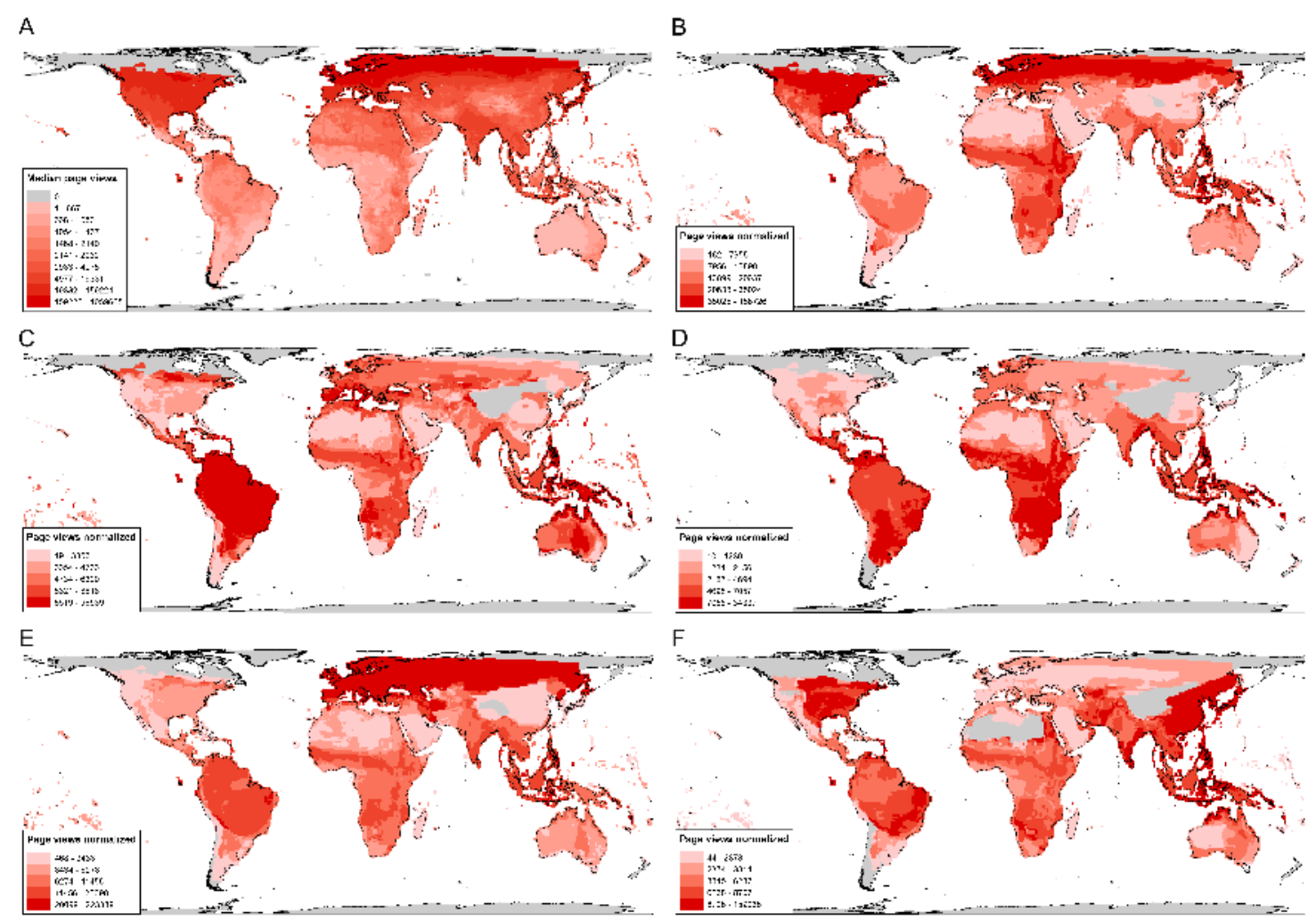


Figure 3:

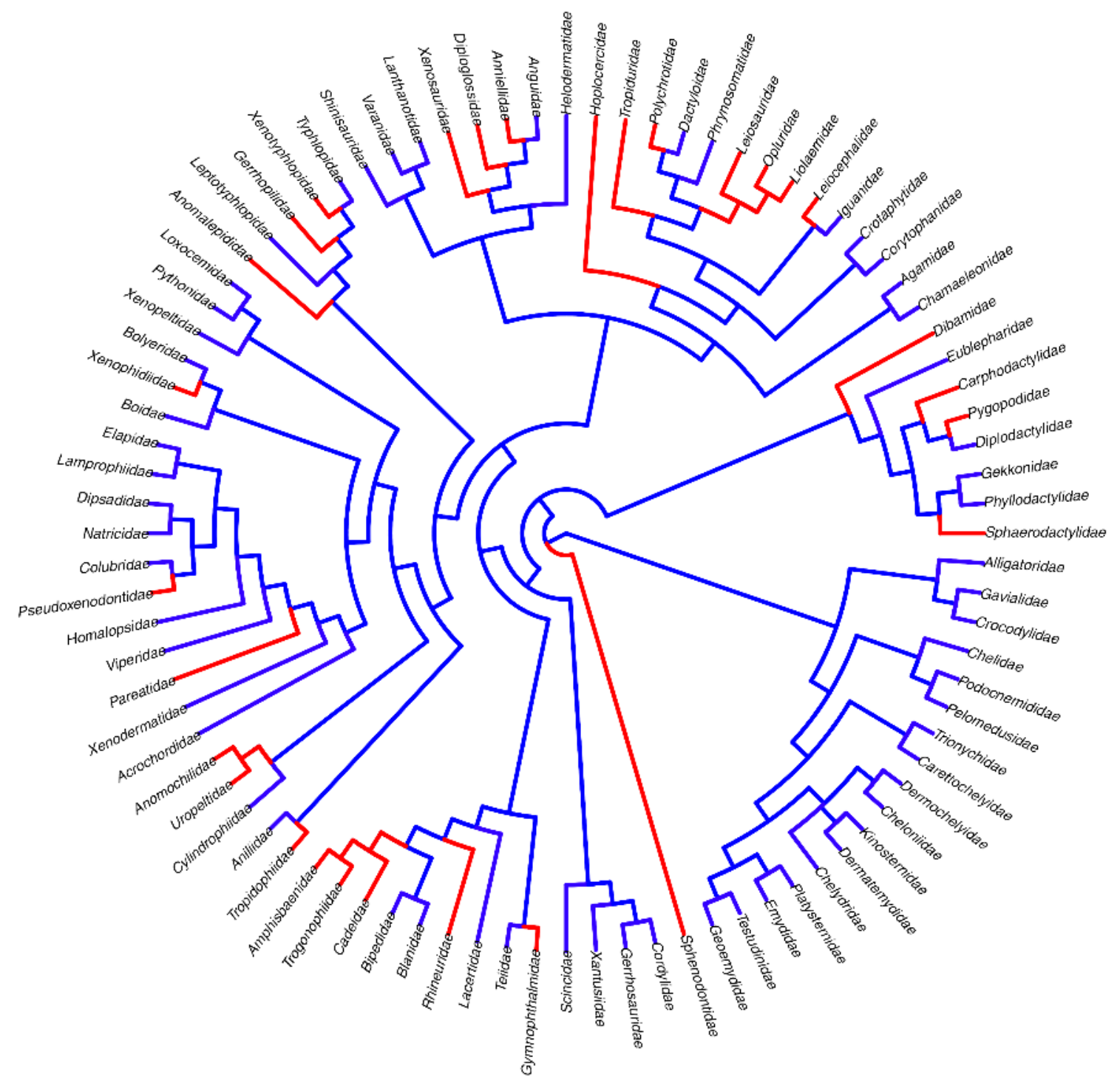

